\title{
Inhibition of viral gene expression by the catalytic RNA subunit of RNase $P$ from Escherichia coli
}

\author{
Fenyong Liu and Sidney Altman ${ }^{1}$ \\ Department of Biology, Yale University, New Haven, Connecticut 06520 USA
}

\begin{abstract}
The catalytic RNA subunit (M1 RNA) of RNase P from Escherichia coli has been converted to an endoribonuclease that specifically cleaves the mRNA that encodes thymidine kinase (TK) of herpes simplex virus 1 (HSV-1). Covalent attachment to the $3^{\prime}$ end of M1 RNA of a sequence complementary to TK mRNA results in very efficient cleavage of the target RNA in vitro. This reaction can be stimulated by proteins extracted from both $E$. coli and HeLa cells. When mouse cells in culture that express the novel RNA construct are infected with HSV-1, the levels of both TK mRNA and protein are reduced by $\sim 80 \%$ as compared with cells that either do not express the novel RNA construct or express constructs with certain deletions that are known to abolish the catalytic activity of M1 RNA.
\end{abstract}

[Key Words: RNA enzyme; gene inactivation; herpes simplex virus; thymidine kinase]

Received November 3, 1994; revised version accepted January 20, 1995

Ribonuclease $\mathrm{P}(\mathrm{RN}$ ase $\mathrm{P})$ is a ribonucleoprotein that is essential for the biosynthesis of the $5^{\prime}$ termini of tRNAs (Altman et al. 1993). In Escherichia coli this enzyme consists of a catalytic RNA subunit (Ml RNA) and a protein subunit (C5 protein) (Darr et al. 1992; Altman et al. 1993). M1 RNA itself cleaves precursors to tRNAs (ptRNAs) and other small RNAs in E. coli (Fig. 1A) in vitro (Guerrier-Takada et al. 1983; Liu and Altman 1994). A minimal, model substrate for M1 RNA and the RNase P holoenzyme (M1 RNA plus C5 protein) contains only the equivalent of the acceptor stem and the $\mathrm{T}$ stem of a ptRNA molecule (McClain et al. 1987; Forster and Altman 1990a). Moreover, the $5^{\prime}$ leader sequence and the $5^{\prime}$ proximal sequence of the acceptor stem, when hydrogen-bonded as a separate oligonucleotide to the $3^{\prime}$ proximal sequence of the acceptor stem [a construct designated an external guide sequence $\{E G S \mid]$, can also be cleaved by M1 RNA or RNase P (Fig. 1B). This observation led us to a novel strategy for gene inactivation whereby an EGS that binds to and targets a specific mRNA (e.g., $\beta$-galactosidase mRNA) such that the mRNA can be cleaved by M1 RNA or RNase P (Li et al. 1992). One limitation of this method is the relatively weak binding of the target RNA to the enzyme, namely, MI RNA. However, if the EGS is included as part of the enzyme (M1 RNA), it becomes possible to increase both the strength of binding of the substrate and the efficiency of cleavage. Self-cleaving conjugates of Ml RNA and ptRNA have been described previously (Altman 1989;

${ }^{1}$ Corresponding author.
Kikuchi et al. 1993; Frank et al. 1994) but have not, to our knowledge, been exploited as sequence-specific endonucleases in the manner described here.

To further our understanding of catalysis by MI RNA and also to design strategies for efficient cleavage by EGS-based RNase $\mathrm{P}$, we constructed a derivative of $\mathrm{Ml}$ RNA, which we call MIGS RNA, by linking a guide sequence (GS) to M1 RNA (Fig. 1C). We show that M1GS RNA can act as a sequence-specific endonuclease and can cleave target RNAs that base-pair with the GS just as group I introns do (Zaug et al. 1986). We also demonstrate that a custom-designed MIGS RNA cleaves the mRNA that encodes thymidine kinase (TK) of human herpes simplex virus 1 (HSV-1) in vitro. Furthermore, when MIGS RNA is expressed in mammalian cells in tissue culture, it reduces the level of expression of TK by decreasing the amount of the target TK mRNA.

\section{Results}

Cleavage of model substrates by M1GS RNA in vitro

The HSV-1 TK gene has been well characterized (for review, see Roizman and Sears 1990). Although the TK gene product is not essential for viral replication in tissue culture cells, because it is so well studied we have used it as a model target for gene inactivation by MIGS RNA. DNA encoding a GS (TK 13) that contains a sequence of 13 nucleotides complementary to the $5^{\prime}$-terminal sequence of mRNA for HSV-1 TK protein was covalently linked to the $3^{\prime}$ end of DNA that encoded M1 RNA (Fig. 2A). The RNA transcript of this construct, 
(A)

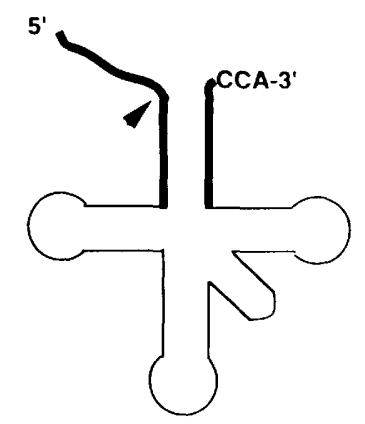

ptRNA
(B)
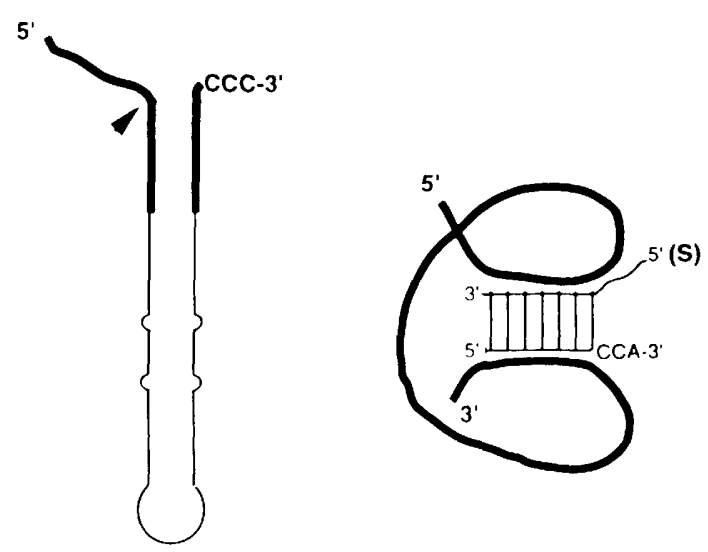

(C)

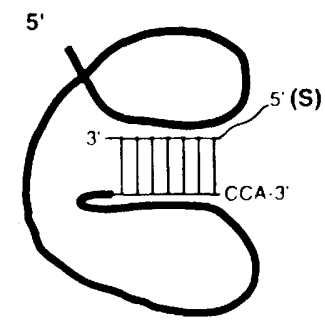

Figure 1. (A) Schematic representation of natural substrates (precursor tRNA and 4.5S RNA) for ribonuclease P and M1 RNA from E. coli. The structural components common to both precursor tRNA and 4.5S RNA are boldface; they are equivalent to 7 bp of the acceptor stem of a tRNA. The site of cleavage by RNase P or MI RNA is marked with an arrowhead. (B) Schematic diagram of M1 RNA in a complex with a substrate that consists of an EGS hybridized with a target RNA (S). The MI RNA sequence is boldface. (C) Schematic diagram of an MIGS RNA construct to which a target RNA (S) has hybridized. In $B$ and $C$ the stem structure formed between the target RNA and either the EGS RNA or MIGS RNA is shown as 7 bp to mimic the structure of the tRNA acceptor stem; it can be varied from 5 to $19 \mathrm{bp}$ as described in the text and in previous studies (Li et al. 1992).

M1TK13, cleaved target RNA, tk7 (Fig. 2B, lane 7), that contains 7 nucleotides of the $5^{\prime}$ sequence of TK mRNA and an unrelated sequence of 5 nucleotides that serves as a leader sequence (Fig. 2A; McGeoch et al. 1988). Cleavage in the target occurs at position 5, yielding two cleavage products of 5 and 7 nucleotides in length, respectively. MITK13 remains unchanged during the reaction, as expected of a true enzyme, as only labeled, full-length MITK13 RNA is detected after incubation of the reaction mixture (data not shown). Attachment of GSs to the $3^{\prime}$ end, rather than to the 5' end, of M1 RNA in the construction of MIGS RNA is preferred because the presence of a $3^{\prime}$-terminal CCA sequence in the GS is important for maximum efficiency of cleavage. Furthermore, additional sequences downstream from the CCA sequence lower the rate of cleavage of substrates (data not shown).

MIGS RNA only cleaves substrates that are complementary to the GS. As shown in Figure 2B (lanes 3,7), M1TK13 RNA can cleave substrate tk 7 but not substrate cat7, which contains a sequence of 7 nucleotides from the mRNA for chloramphenicol acetyltransferase (CAT). However, M1CAT13 RNA, in which the GS contains a sequence of 13 nucleotides complementary to CAT mRNA, can efficiently cleave cat 7 but not tk7 (lanes 2,5 . Therefore, MIGS RNA appears to act as a sequencespecific endonuclease, recognizing its substrates through specific base-pairing between the GS and the target sequence, as has also been shown by Frank et al.
(1994) with somewhat different constructs. To determine whether longer RNAs can be specifically cleaved by these new RNA enzymes, uniformly ${ }^{32} \mathrm{P}$-labeled fragments of the TK (450 nucleotides) and CAT (550 nucleotides) mRNA sequences (Fig. 3A) were incubated with either MITK13 RNA or MICAT13 RNA. Sequence-specific and efficient cleavage of these RNA substrates by the appropriate RNA enzymes is shown in Figure 3B.

A set of RNA enzymes, designated M1TK19, M1TK16, MITK13, M1TK10, and M1TK5, were constructed in which the GSs contained sequences of 19,16,13,10, and 5 nucleotides complementary to the TK mRNA sequence, respectively (Fig. 4A), to relate the length of the target helix to efficiency of cleavage. The substrate tk 46 , which contains a TK mRNA sequence of 46 nucleotides, was cleaved by all of the constructs (Fig. 4B, lanes 9-14), and the cleavage site was determined to be at position G21 (data not shown), as expected (Fig. 4A). Further kinetic analysis of cleavage of substrate tk 46 by M1TK16, M1TK13, M1TK10, and M1TK5 RNAs was also performed (Table 1). Values of $k_{\text {cat }}$ increased in the rank order from M1TK5 to M1TK16 RNA. Values of $K_{\mathrm{m}}$ decreased progressively with increasing length of the duplex. The overall $K_{\mathrm{m}}$ of the reaction undoubtedly involves both the substrate binding to the GS sequence (helix formation) and docking of the double helical segment in the active site of M1 RNA, a complex process. There was one exception to the rule of increasing $k_{\text {cat }}$ with length of GS: $k_{\text {cat }}$ decreased from M1TK13 to 
A
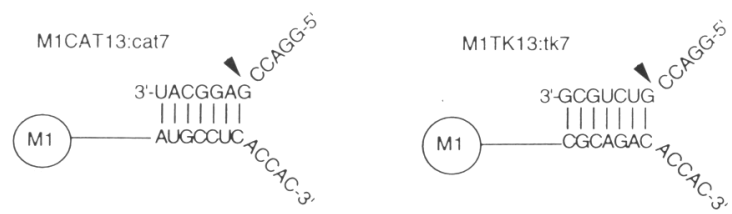

B

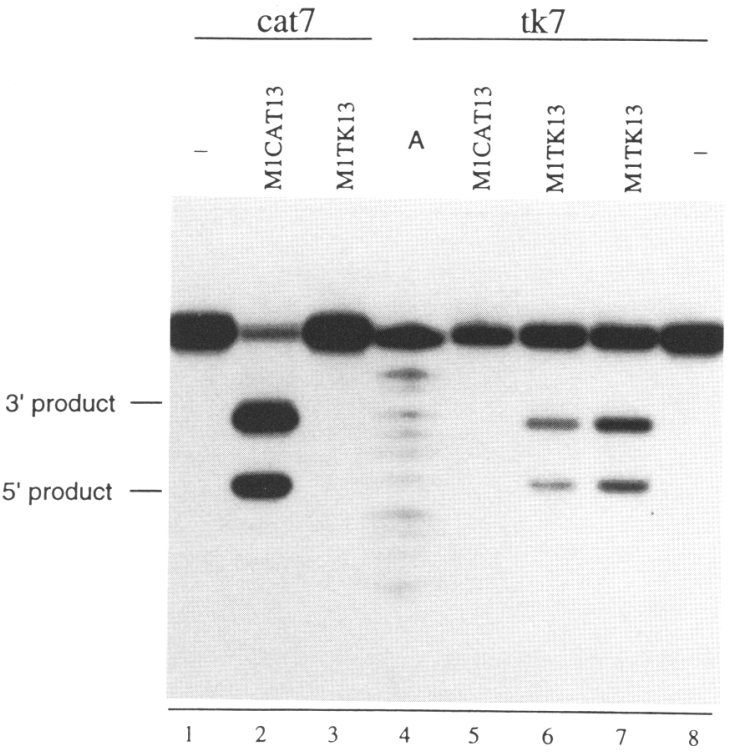

Figure 2. Sequence-specific cleavage of a small substrate by MIGS RNA. (A) Schematic representation of complexes that are formed by MIGS RNA and two substrates. $(B)$ Autoradiograph of cleavage products generated by M1GS RNA constructs. RNA substrates cat 7 and $t \mathrm{k} 7$ were incubated either alone (lanes 1,8), with MICAT13 RNA (lanes 2,5), or with MITK13 RNA (lanes $3,6,7)$. Twice as much MITK13 RNA was used in the reaction shown in lane 7 as was used in that shown in lane 6 . Lane 4 shows a size ladder obtained by alkaline treatment of $t \mathrm{k} 7$ RNA. Cleavage reactions were carried out in buffer A $150 \mathrm{~mm}$ Tris- $\mathrm{HCl}$ at $\mathrm{pH} 7.5,100 \mathrm{mM} \mathrm{NH}_{4} \mathrm{Cl}, 100 \mathrm{mM} \mathrm{MgCl}_{2}$ lat $50^{\circ} \mathrm{C}$. Further experimental details are given in Materials and methods.

M1TK16. This last result can be explained if release of product becomes the rate-limiting step in the reaction governed by M1TK16 RNA [compare overall cleavage rates $\left(k_{\text {cat }} / K_{\mathrm{m}}\right)$ under single- and multiple-turnover conditions [Fersht 1985)]. Further analysis of the reaction with M1TK13 showed that $\sim 5$ pmoles of tk46 were cleaved by 1 pmole of M1TK13 in $30 \mathrm{~min}$, indicating that the RNA enzyme turns over five times during the incubation period (data not shown). This result is consistent with the value of $k_{\text {cat }}$ measured by classical MichaelisMenten kinetic analysis (see Table 1).

M1GS RNAs act more efficiently than does M1 RNA in the classic cleavage reaction in trans. MITK16 cleaves tk46 at least 10 times faster than does M1 RNA with a separated (nonintegrated) GS, TK16 (Fig. 4B, lanes 1-7; cf. lanes 4 and 7) under equivalent experimental conditions. Moreover, MIGS RNA cleaves its substrates more efficiently in buffers that mimic physiological conditions more closely in terms of magnesium ion concentration (10 $\mathrm{mM} \mathrm{MgCl}_{2}$ ) than does Ml RNA with a sepa- rated GS in buffers that contain $100 \mathrm{mM} \mathrm{MgCl}_{2}$, an indication that the high concentrations of $\mathrm{Mg}^{2+}$ ions are needed to mediate binding of the substrate to Ml RNA alone (Kazakov and Altman 1991; Smith and Pace 1993). Further analysis of the cleavage reaction of M1GS RNA indicated that the cleavage proceeds optimally at a temperature of $62^{\circ} \mathrm{C}$, at concentrations of monovalent cations of $100 \mathrm{mM}$, and at concentrations of $\mathrm{Mg}^{2+}$ ions of 60-100 $\mathrm{mm}$ (data not shown).

To prove that the catalytic activity of MIGS RNA resides in the sequence that encodes M1 RNA, a set of MITK RNAs was constructed in which each RNA had a deletion in a different region of the MI RNA sequence but in which each had the same GS, TK13. The various M1 RNA deletion mutants (e.g., $\Delta 167-377, \Delta 1-163, \Delta 65$, etc.) lack the catalytic activity needed to process pretRNAs /Guerrier-Takada et al. 1989; Guerrier-Takada

A

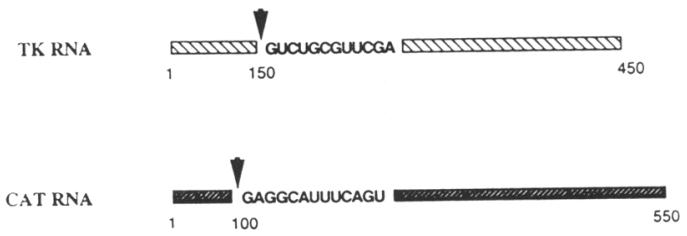

B
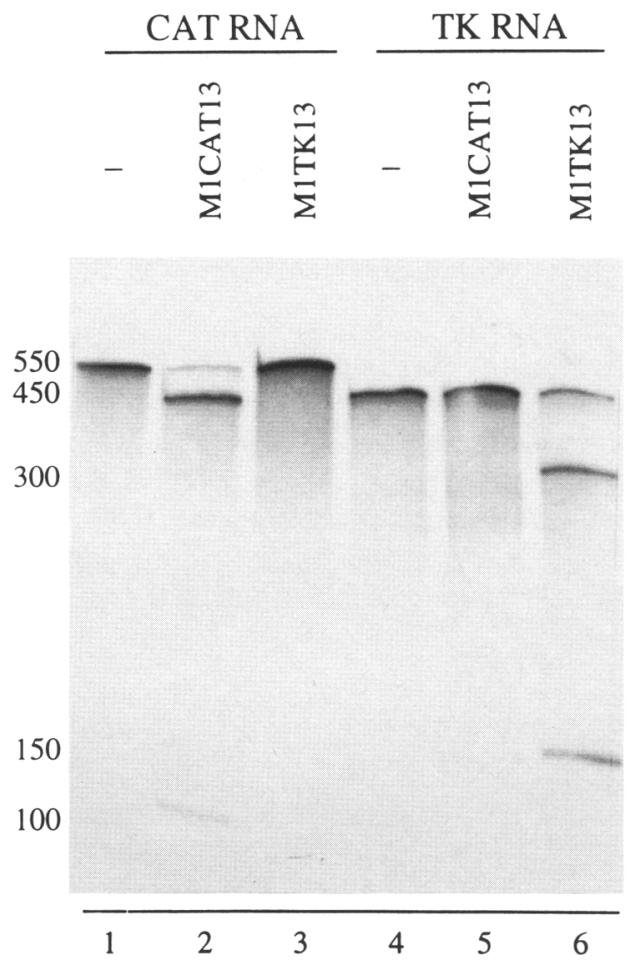

Figure 3. Sequence-specific cleavage of TK and CAT RNA sequences by MIGS RNA. (A) The two 13-nucleotide segments highlighted in the TK RNA and CAT RNA sequences are complementary to the guide sequences in M1TK13 and MICAT13 RNAs, respectively. $(B)$ Uniformly labeled CAT and TK RNAs $(2 \mathrm{nM})$ were incubated alone (lanes 1,4$)$ or with either M1TK13 or MICAT13 RNA ( $20 \mathrm{nM}$ ) for $45 \mathrm{~min}$ at $37^{\circ} \mathrm{C}$ in buffer $\mathrm{B}$ in the presence of $20 \mathrm{mM} \mathrm{MgCl}_{2}$ (lanes 2,3,5,6). 
A
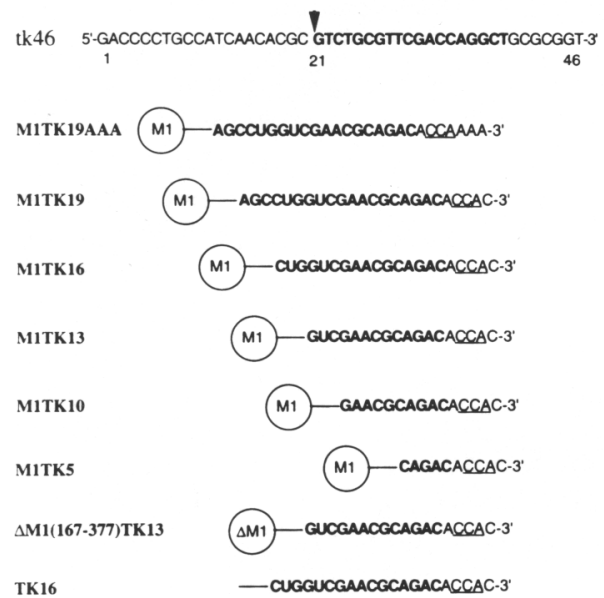

B

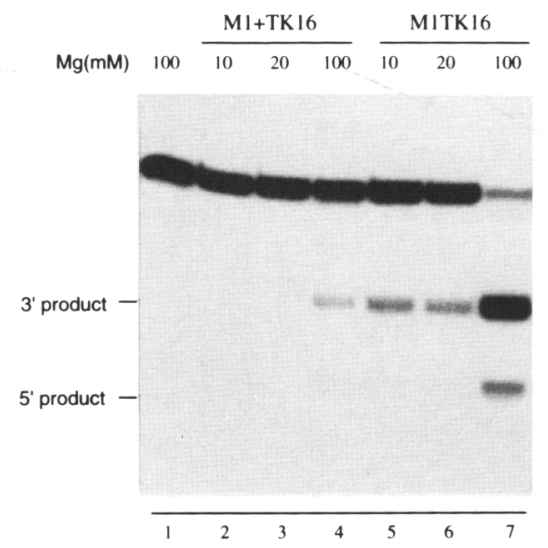

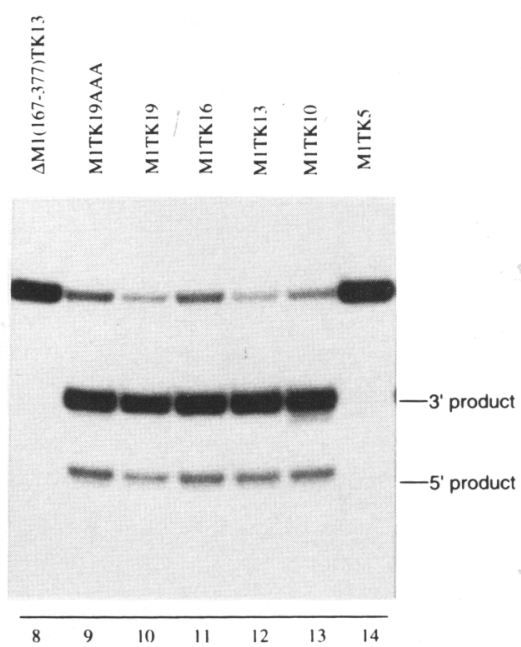

Figure 4. Cleavage of tk46 RNA by MIGS RNAs. (A) Schematic representation of the tk46 substrate sequence and the structure of RNA enzymes used in these studies. The arrowhead marks the expected site of cleavage. The sequences shown in the MIGS RNAs are the GSs that contain the $3^{\prime}$-CCA sequence and the sequence complementary to the TK sequence (in boldface type). (B) Autoradiograph of tk46 cleavage results by either MI RNA and a separated GS (lanes 2-4) or the M1GS RNAs (lanes 5-14). No RNA enzyme was added to the reaction mixture in lane 1 . RNA substrate tk46 (20 nM) was incubated with $20 \mathrm{~nm}$ enzymes as specified. Reactions were carried out either in buffer B that contained different concentration of $\mathrm{MgCl}_{2}$ as specified (lanes 1-7) or in buffer A (lanes 8-14). The EGS RNA, TK16, used in lanes 2-4, was at the saturating concentration (>60 nM). The cleavage products in lane 14 are visible in the original autoradiograph. More experimental details are given in Materials and methods.

and Altman 1992), and MlGS RNA constructs with these deletion mutants and the linked TK13 sequence were unable to cleave tk46 (Fig. 4B, lane 8; other data not shown).

\section{Stimulation of the activity of M1GS RNA by proteins}

C5 protein, the protein subunit of RNase P from E. coli, increases the rate of cleavage of natural substrates by MI RNA (Guerrier-Takada et al. 1983, Reich et al. 1988). C5 protein also stimulates the cleavage by M1GS RNA by a factor of 30 or more (Fig. 5, cf. lanes 4 and 5). Furthermore, cleavage by M1GS RNA can be stimulated at least fivefold by a partially purified preparation of human RNase P (Fig. 5, cf. lanes 1 and 5). This enhancement in

Table 1. Kinetic parameters of reactions catalyzed by various M1GS RNA constructs

\begin{tabular}{lcccc}
\hline Enzyme & $K_{\mathrm{m}}(\mu \mathrm{M})$ & $k_{\mathrm{cat}}\left(\mathrm{min}^{-1}\right)$ & \multicolumn{2}{c}{$k_{\mathrm{cat}} / K_{\mathrm{m}}$} \\
\hline M1TK16 & 0.08 & 0.14 & 1.6 & $2.4^{*}$ \\
M1TK13 & 0.09 & 0.21 & 2.3 & $2.4^{*}$ \\
M1TK10 & 0.15 & 0.10 & 0.7 & $0.7^{*}$ \\
M1TK5 & 0.22 & 0.03 & 0.1 & $0.1^{*}$ \\
\hline
\end{tabular}

Kinetic parameters were governed by different MIGS RNAs under single-turnover (marked with an asterisk) and multipleturnover conditions. In brief, cleavage assays were performed in buffer A $150 \mathrm{~mm}$ Tris- $\mathrm{HCl}$, at $\mathrm{pH} 7.5,100 \mathrm{mM} \mathrm{NH}_{4} \mathrm{Cl}, 100 \mathrm{~mm}$ $\mathrm{MgCl}_{2}$ ) at $50^{\circ} \mathrm{C}$. Further experimental details are described in Materials and methods. The values of kinetic parameters determined in different experiments exhibit a variation of $<20 \%$.

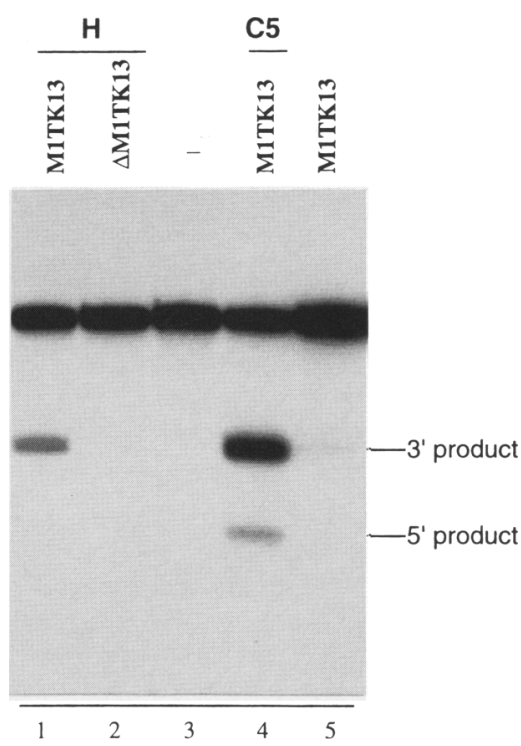

Figure 5. Stimulation of the cleavage by MIGS RNA of tk46 RNA by $C 5$ protein and human RNase $P$ that had been partially purified from HeLa cells. The target tk46 RNA was incubated with MITK13 RNA (lanes 1,4,5), alone (lane 3) or with $\triangle M 1(167-377) T K 13$ RNA (lane 2). Partially purified human RNase $\mathrm{P}(\mathrm{H})$ (20 units) was added to a $20-\mu$ l reaction analyzed in lanes 1 and 2, and C5 protein from E. coli (C5) (400 nM) was added to the reaction analyzed in lane 4 . C5 protein and human RNase P were purified as described previously (Vioque et al. 1988; Bartkiewicz et al. 1989). Reaction mixtures were incubated for $30 \mathrm{~min}$ at $37^{\circ} \mathrm{C}$ in buffer B that contained $5 \mathrm{mM} \mathrm{MgCl}$. Further experimental details are given in Materials and methods. 
rate was anticipated as it had been shown previously that protein from a crude preparation of human (HeLa cells) RNase $P$ can enhance the cleavage of ptRNA by Ml RNA (Gold and Altman 1986). The rate stimulation cannot be ascribed to residual human $\mathrm{RN}$ ase $\mathrm{P}$ activity as it, alone, cannot cleave substrate tk46 in complexes with catalytically inactive $\Delta \mathrm{M} 1(167-377) \mathrm{TK} 13 \mathrm{RNA}$ (Fig. 5, lane 2). The last result is consistent with observations that a simple stem-loop structure can serve as a substrate for M1 RNA but not for eukaryotic RNase P [i.e., human and Xenopus laevis RNase P (Carrara et al. 1995; Yuan and Altman 1995)]. No stimulation of substrate tk46 cleavage by M1TK13 RNA was observed when fractions devoid of human RNase P activity were used (data not shown). We anticipate, therefore, that when MIGS RNA constructs are present in mammalian cells (see below), their activity should be enhanced by endogenous proteins.

\section{Expression in vivo of M1GS RNA}

To express MIGS RNA in mammalian cells, retroviral constructs, M1TK and $\triangle \mathrm{MlTK}$, were generated by cloning genes for M1TK13 and $\Delta M 1(163-377) T K 13$ into the retroviral vector LXSN (Miller and Rosman 1989) under the control of a mouse U6 snRNA promoter (Fig. 6A; Yuan et al. 1992; Das et al. 1988). An additional retroviral DNA construct, NB2, containing the U6 promoter and an EGS (NB2) that targets the mRNA that encodes the PB2 protein of human influenza virus (Fig. 6; D. Plehn-Dujowich and S. Altman, unpubl.), was used as a control.

The targeted cleavage site of TK mRNA expressed in cells infected with HSV-1 appears to be modifiable by dimethyl sulfate (DMS) in vivo (data not shown; Peattie and Gilbert 1980; Inoue and Cech 1985; Climie and Friesen 1988; Ares and Igel 1990), an indication that this site might be accessible for binding to MlGS in vivo. Amphotropic packaging cells (PA317; Miller and Rosman 1989) were transfected with retroviral vector DNAs to produce retroviruses that encoded the genes for M1GS RNA. Subsequently, ecotropic packaging cells ( $\psi \mathrm{CRE}$; Danos and Mulligan 1988) were infected with these retroviruses, and cells expressing the retroviruses and ribozymes were cloned. Stable expression of MIGS RNAs was demonstrated by an RNA protection assay with a probe that was complementary to the sequence of $\mathrm{Ml}$ RNA (Fig. 6) and RNA isolated from these cell lines. Furthermore, RNA extracted from M1TK-expressing cells can cleave substrate tk46 in vitro, whereas RNA extracted from the parental $\psi \mathrm{CRE}$ cells, cells that expressed NB2 RNA and $\triangle$ M1TK RNA do not show cleavage activity (data not shown). These results demonstrate that the M1TK RNA that is expressed in cultured cells was intact and catalytically active.

Inhibition of TK expression of HSV-1 in cells that express M1GS RNA

Cells were infected with (HSV-1) at a multiplicity of in-
A

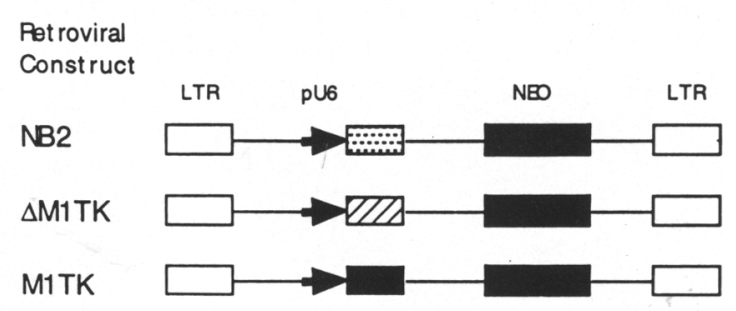

B

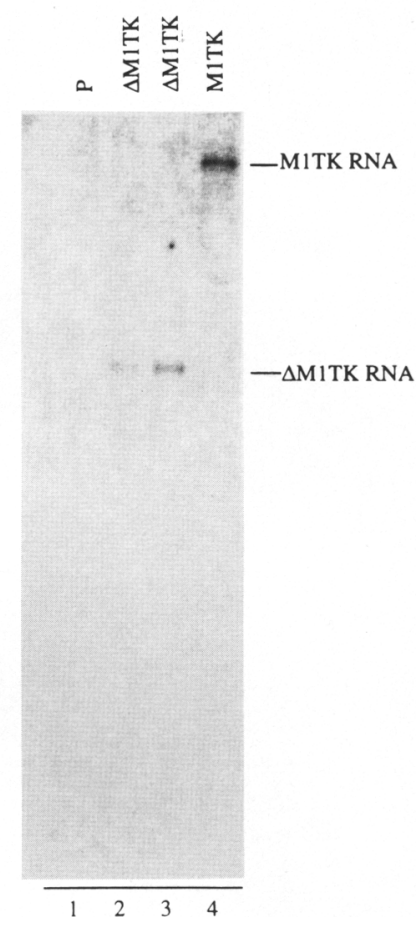

Figure 6. Construction and expression of retroviral vectors that contained MIGS RNA. (A) Schematic representation of retroviral vectors $(\triangle M 1 T K, M 1 T K$, and NB2) contained MIGS RNAs or an EGS sequence complementary to the mRNA coding for the influenza viral protein PB2. $(B)$ RNase protection analysis of RNA isolated from parental $\psi$ CRE cells (lane 1) and from cell lines that expressed $\triangle$ MITK RNA (lanes 2,3) and MITK RNA (lane 4). The RNA probe contained a sequence complementary to M1 RNA (nucleotides 1-277). Products of the RNase protection assay were separated in $8 \mathrm{M}$ urea $/ 8 \%$ polyacrylamide gels, and the gels were then subjected to autoradiography. The protection products corresponding to the full-length retroviral transcripts, transcribed from the LTR promoter, remained at the top of the gel and are not shown here.

fection (moi) of $0.05-0.1$. Levels of TK mRNA in the infected cells were determined by an RNase protection assay with an RNA probe (TK probe) that contained a sequence of 87 nucleotides complementary to the 5' proximal sequence of TK mRNA. An RNA probe $(\alpha 47)$, containing a sequence of 181 nucleotides complementary to the overlapping regions of $\alpha 47, \mathrm{Us} 10$, and Us 11 mRNAs encoded by HSV-1, was used to determine the levels of these latter mRNAs (McGeoch et al. 1988; Roizman and Sears 1990). The levels of the latter RNAs were used as internal controls for quantitation of expres- 
sion of TK mRNA. Figure 7A shows the results (which are also summarized graphically in Fig. 8) of the RNase protection experiments with both the TK and $\alpha 47$ probes. A reduction of $\sim 80 \pm 5 \%$ (average of four experiments) in the level of TK mRNA expression was ob-

A

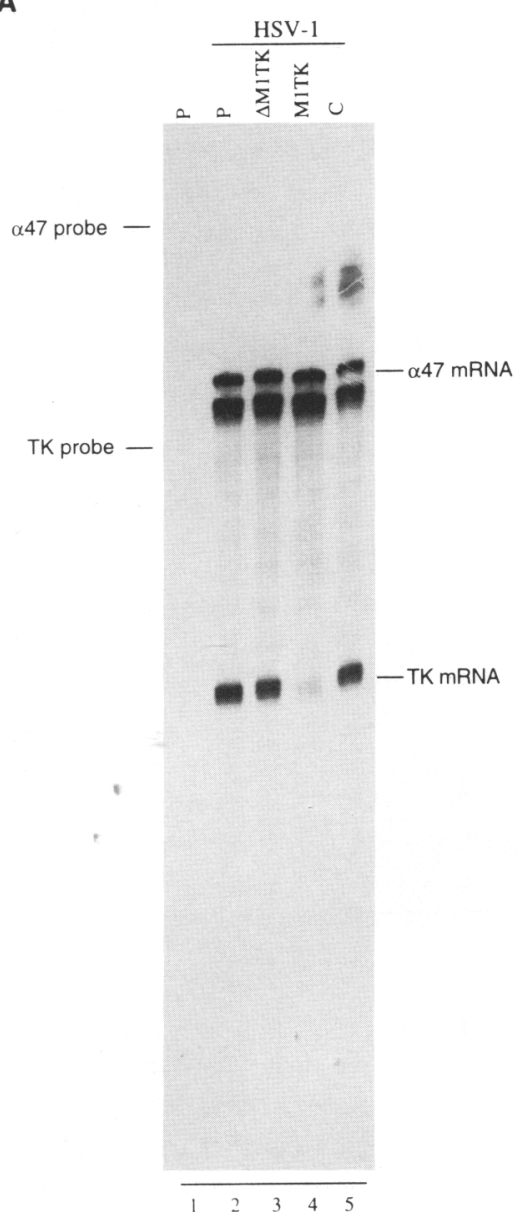

B
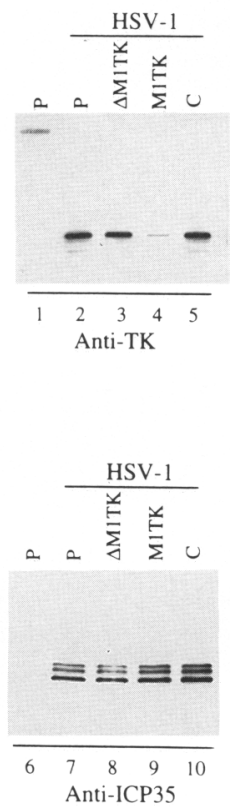

Figure 7. Levels of expression of TK mRNA, as determined by an RNase protection assay $(A)$, and levels of expression of TK protein, as determined by Western blot analysis with a chemiluminescent substrate $(B)$. In $A$, RNase protection assays were performed as described previously (Yuan et al. 1992). Total cytoplasmic RNA was isolated from parental $\psi$ CRE cells [P (lanes 1,2)] or from cell lines expressing NB2 RNA [C (lane 5)], $\triangle M 1 T K$ RNA (lane 3), and M1TK RNA (lane 4). The cells were either mock-infected (lane 1) or infected with HSV-1 (lanes 2-5). The two probes are designated TK and $\alpha 47$ probe, respectively. The protected products corresponding to TK mRNA (indicated) and the overlapping transcripts of $\alpha 47$, Us10, and Us 11 mRNA $\{47$ mRNA) were $\sim 90$ and 180 nucleotides long, respectively. In $B$, protein samples isolated from cells that expressed specified retroviral vectors and had been infected with HSV-1 were separated in two identical SDS-polyacrylamide gels and transferred electrically to two identical membranes. Lane assignments are the same as in $A$. One membrane was allowed to react with a monoclonal antibody (Anti-ICP35) against HSV-1 (F) ICP35 protein; the other was stained with the polyclonal antibody (Anti$\mathrm{TK}$ ) against HSV-1(F) TK protein. Experimental details are given in Materials and methods.

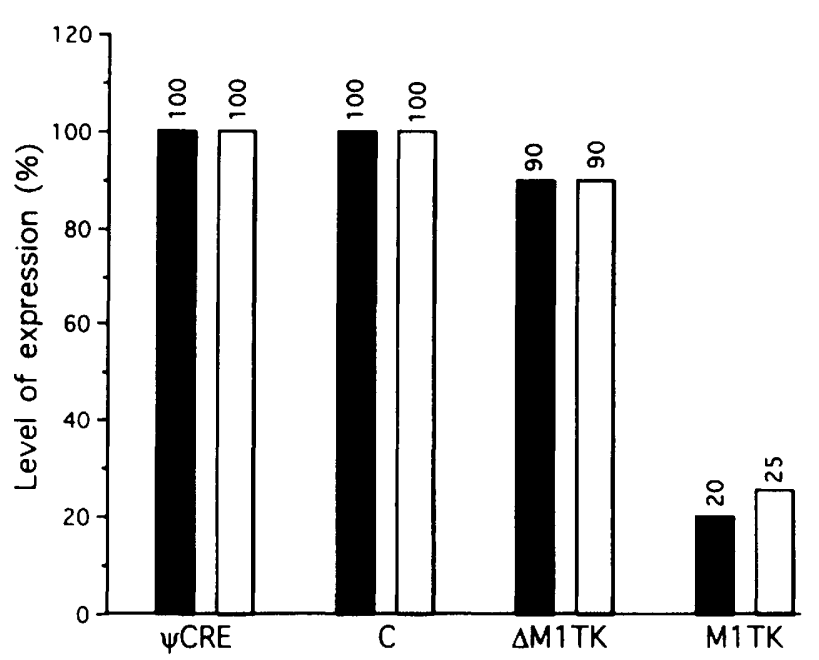

Figure 8. Schematic representation of expression levels of TK mRNA and protein in $\psi \mathrm{CRE}$ cells and in other cell lines described in the text and the legend to Fig. 7. Values are averages of results from four independent experiments. Results from the four experiments varied within $5 \%$ in absolute terms. (Solid bars) TK mRNA; (open bars) TK protein. Both RNA probes and antibodies were used in great excess of the detected RNA species and antigens.

served in cells that expressed MITK RNA, whereas cells that expressed $\triangle$ MITK RNA only exhibited a reduction of $9 \pm 3 \%$ (average of four experiments). Thus, it appears that cleavage of TK mRNA by MITK RNA did occur inside cells, with a subsequent reduction in the level of TK mRNA that could be translated. No products of the cleavage of TK mRNA were detected in our RNase protection assays presumably because these RNAs, which lack either a cap structure or a poly(A) sequence, are rapidly degraded by intracellular RNases (Sambrook et al. 1989).

Protein extracts of the infected cells were analyzed for the presence of the TK polypeptide (Fig. 7B). Polypeptides were transferred to two identical membranes, and one was stained with a TK-specific antibody (anti-TK; Liu and Summers 1988) while the other was stained with a monoclonal antibody against the capsid protein ICP35 of HSV-1 (anti-ICP35; Liu and Roizman 1991). The expression of ICP35 serves as an internal control for the quantitation of TK expression. The results of four independent experiments are summarized in Figure 8: A reduction of at least $76 \pm 5 \%$ (average of four experiments) in the level of TK protein was observed in cells that expressed MITK RNA, whereas a reduction of only $10 \pm$ $4 \%$ (average of four experiments) was seen in cells that expressed $\triangle M 1 T K$ RNA. The low level of inhibition found in cells that expressed $\triangle$ MITK RNA was presumably attributable to an antisense effect.

\section{Discussion}

\section{M1GS RNA functions in gene inactivation}

The discovery of RNA enzymes has led to the availabil- 
ity of new tools for the inactivation of specific genes (Rossi and Sarver 1990; Altman 1993). Sequence-specific endoribonucleases that cleave targeted eukaryotic and viral RNAs have been engineered from self-cleaving RNAs (Hutchins et al. 1986; Zaug et al. 1986; Uhlenbeck 1987; Haseloff and Gerlach 1988; Hampel and Tritz 1989|. Studies both in vitro and in vivo have demonstrated the potential for a promising future for RNA enzymes in the treatment of AIDS and other human diseases (Sarver et al. 1990; Yu et al. 1993). Several criteria must be satisfied if successful targeting is to be achieved. Among these are high efficiency of cleavage, sequence specificity of the RNA enzyme, and efficient delivery of the reagents. Our studies have revealed that a new catalytic RNA construct (M1GS RNA) can be used for cleavage of viral mRNA both in vitro and in vivo. We converted M1 RNA, which acts in trans on many substrates with no apparent sequence specificity, to MIGS RNA, which cleaves one particular substrate in a reaction governed by sequence specificity. Furthermore, we have shown that a custom-designed MITK RNA, which cleaves the TK mRNA in vitro, can be expressed stably in mammalian cells and can reduce the level of expression of TK by $\geqslant 75 \%$ when these cells are infected with HSV-1. The reduction in the level of expression of TK that can be ascribed to the antisense effect of the (internal) GS is no more than $15 \%$ of the total inhibitory effect. Moreover, the high degree of sequence specificity, which is governed by a GS that hybridizes to a complementary sequence in the substrate, makes our construct suitable for use as a tool for targeting RNAs in vivo. [The optimal length of an antisense sequence for in vivo targeting is $\sim 13$ nucleotides (for review, see Stein and Cheng 1993)l. The extent of inactivation that we observed was very similar to that achieved when endogenous RNase $\mathrm{P}$ is used as the catalytic agent to cleave complexes of target TK mRNA and separate EGSs lexpressed from synthetic genes that have been incorporated stably into human cells in tissue culture; F. Liu, Y. Yuan, and S. Altman, unpubl.).

The activity of M1GS RNA was stimulated in vitro by C5 protein and mammalian proteins. This result suggested that M1GS RNA might function in vivo. Gold and Altman (1986) suggested that C5 protein and protein subunits of human RNase P might bind to homologous sequences and similar structures that are found in both Ml RNA and Hl RNA, the RNA component of RNase P from HeLa cells (Forster and Altman 1990b). However, little is known about the proteins that form part of the human RNase P complex nor is it known whether the proteins that stimulate the MIGS RNA activity are part of that holoenzyme or fortuitously purify with it. Hence, the cleavage reactions by MIGS RNA in cells that contain these sequence-specific binding proteins might be expected to proceed at rates higher than those observed in vitro, particularly in the presence of additional, nonspecific, RNA-binding proteins (RNA chaperones), which are known to stimulate the activity of other RNA enzymes (Tsuchihashi et al. 1993; Bertrand and Rossi 1994; Coetzee et al. 1994; Herschlag et al. 1994). We note that during the course of these studies, Frank et al. (1994) reported the construction of derivatives of M1 RNA similar to those described here but did not demonstrate the function of these constructs in cells.

\section{M1GS RNA as a model for catalysis by M1 RNA}

MIGS RNA can be used to analyze the central role of the analog of the acceptor and T-stem domains of a ptRNA in the binding to and cleavage by M1 RNA of its substrates. The T stem in natural tRNAs, which is coaxially stacked on the acceptor stem, and the acceptor stem itself are critically involved in the interaction with $\mathrm{Ml}$ RNA (McClain et al. 1987; Forster and Altman 1990a, Kahle et al. 1990; Nolan et al. 1993). The base-paired region created by the binding of MIGS RNA to tk 46 can, for example, be considered to be analogous to the continuous helix formed by the acceptor stem and the $\mathrm{T}$ stem. Substrates with a shorter RNA duplex (e.g., M1TK5 and M1TK10), might be unable to participate in all of the enzyme-substrate interactions that are observed between MI RNA and the T and acceptor stems in a pre-tRNA. As a result, weaker binding of substrate and a lower overall rate of cleavage might be expected (see Table 1). Our data are consistent with the observation that a helix of $12 \mathrm{bp}$, similar to that of the acceptor and T stem of a ptRNA, is close to the minimum length for optimal cleavage of substrate.

Our studies with MIGS RNA also demonstrate that the critical substrate-recognition structure can be as small as a helix of $5 \mathrm{bp}$ with a short $5^{\prime}$ leader sequence. This conclusion is consistent with the previous observation that a pseudoknot structure derived from a plant viral RNA, which contains an RNA helix of only $4 \mathrm{bp}$, can serve as a substrate for MI RNA and RNase P (Guerrier-Takada et al. 1988). The similarity between MIGS RNA and MI RNA, as revealed by our data, supports the hypothesis that the interactions needed to position the cleavage site of substrates at the active center in M1GS reflects faithfully the interactions that are necessary between MI RNA and ptRNA substrates.

\section{Materials and methods}

Construction of plasmids, catalytic RNAs, and RNA substrates for studies in vitro

DNA templates for transcription in vitro of RNA substrates $t k 7$, tk 46 , and cat 7 were constructed by annealing the $T 7$ promotercontaining oligonucleotide OliT7 (5'-TAATACGACTCACTATAG-3') with oligonucleotides Olitk $7\left(5^{\prime}\right.$-CGCAGACGGTCCTATAGTGAGTCGTATTA-3'), OliTK46 (5' -ACCGCGCAGCCTGGTCGAACGCAGACGCGTGTTGATGGCAGGGGTCTATAGTGAGTCGTATTA-3'), and Olicat7 (5'-ATGCCTCGGTCCTATAGTGAGTCGTATTA-3'), respectively. Plasmids pTK117 and pTK146, in which the DNA sequences coding for M1 RNA and mutant MI RNA with a deletion from nucleotides 167 to 377 (Guerrier-Takada and Altman 1992), respectively, are under the control of the T7 RNA polymerase promoter, are derivatives of pUC19. The DNA templates for M1TK19, MlTK16, MITK13, MITK10, M1TK5, and MICAT13 were constructed by the polymerase chain reaction (PCR) with the 
gene for M1 RNA as found in plasmid pTK117 with OliT7 as the $5^{\prime}$ primer oligonucleotide and 3 ' primers that contained the appropriate GSs. The $3^{\prime}$ primers were OliTK 19 (5'-GTGGTGTCTGCGTTCGACCAGGCTATGACCATG-3'), OliTK16 (5' -GTGGTGTCTGCGTTCGACCAGTATGACCATG-3'), OliTK13 (5'-GTGGTGTCTGCGTTCGACTATGACCATG-3'), OliTK10 (5'-GTGGTGTCTGCGTTCTATGACCATG- $\left.3^{\prime}\right)$, OliTK5 $\left(5^{\prime}\right.$ GTGGTGTCTGTATGACCATG-3'), and OliCAT13 (5'-GTGGTGAGGCATTTCAGTTATGACCATG-3'). The 3' proximal sequences of 10 nucleotides serve as the primers for the PCR with the pUCl9 sequence. The underlined sequences and the bold sequences correspond to the 3 '-CCAC sequence and the GSs, respectively. The DNA template for $\Delta \mathrm{M} 1(167-377) T K 13$ RNA was constructed by PCR with the sequence for MI RNA in pTK146 and primers OliT7 and OliTK13. The DNA template for EGS TK 16 was constructed by PCR with the $5^{\prime}$ primer OliT7 and the $3^{\prime}$ primer OliTK 16 from DNA template pUCT7, which was derived from pUC19 by insertion of a T7 promoter sequence into the BamHI site. The CAT mRNA fragment of 550 nucleotides was synthesized with T7 RNA polymerase and EcoRI-digested pCAT-1 plasmid DNA (Promega, Inc.), whereas the TK mRNA fragment of 450 nucleotides was synthesized from plasmid pTK101 DNA in which the sequence for TK mRNA is under control of the T7 promoter.

\section{Assays for cleavage by M1GS RNA}

RNA enzyme (20 nM) and substrate (50 $\mathrm{nM})$, either uniformly labeled with $\left[\alpha^{-32} \mathrm{P}\right] \mathrm{GTP}$ or $5^{\prime}$ end-labeled with $\left[\gamma^{-32} \mathrm{P}\right] \mathrm{ATP}$, were incubated for $30 \mathrm{~min}$ at $37^{\circ} \mathrm{C}$ or $50^{\circ} \mathrm{C}$ in buffer $\mathrm{A}(50 \mathrm{mM}$ Tris at $\mathrm{pH} 7.5,100 \mathrm{mM} \mathrm{NH}_{4} \mathrm{Cl}, 100 \mathrm{~mm} \mathrm{MgCl}_{2}$ ) or buffer B (50 mM Tris at $\mathrm{pH} 7.5,100 \mathrm{mM} \mathrm{NH}{ }_{4} \mathrm{Cl}$ ) that contained $\mathrm{MgCl}_{2}$ at various concentrations. Reactions were stopped by the addition of $8 \mathrm{M}$ urea, and the cleavage products were then separated on either $15 \%$ or $20 \%$ polyacrylamide gels that contained $8 \mathrm{M}$ urea. C5 protein and human RNase $P$ protein were purified from $E$. coli and HeLa cells, respectively, as described previously (Vioque et al. 1988; Bartkiewicz et al. 1989; Yuan and Altman 1994). The RNase $\mathrm{P}$ holoenzyme from $E$. coli was assembled by mixing M1 RNA and C5 protein at a molar ratio of 1:20.

Assays to determine kinetic parameters under single- and multiple-turnover conditions were performed as described previously (Guerrier-Takada et al. 1983; Liu and Altman 1994). Cleavage was assayed at various concentrations of substrate (in 2- to 20 -fold excess over enzyme concentration), both above and below the $K_{\mathrm{m}}$ for the substrate. Aliquots were withdrawn from the reaction mixtures at regular intervals, and the cleavage products were separated in polyacrylamide-urea gels. Quantitation was carried out with a PhosphorImager (Molecular Dy. namics). The values of $K_{\mathrm{m}}$ and $k_{\text {cat }}$ were obtained from Lineweaver-Burk double reciprocal plots. In single turnover experiments, trace amounts of substrates were used, and the concentrations (1 nM) was much lower than the $K_{\mathrm{m}}(>80 \mathrm{nM})$. The enzyme concentration ranged from $5 \mathrm{~nm}$ to $200 \mathrm{~nm}$. The observed rate of cleavage $\left(k_{\text {obs }}\right)$ was determined, and the value of $k_{\mathrm{cat}} / K_{\mathrm{m}}$ was obtained from the equation $k_{\mathrm{cat}} / K_{\mathrm{m}}=k_{\mathrm{obs}} /[\mathrm{E}]$, where $[E]$ is the concentration of the enzyme.

\section{Viruses, cells and antibodies}

The properties of HSV-I $(F)$, a prototype of human herpes simplex virus 1 (a gift from B. Roizman of the University of Chicago, IL) have been described elsewhere (Ejercito et al. 1968). The retroviral vector, LXSN, and retroviral packaging cell lines [PA317 (amphotropic) and $\psi \mathrm{CRE}$ (ecotropic)] were gifts from D. DiMaio of the Yale University School of Medicine (New Haven,
CT). These cells were maintained and propagated as described previously (Danos and Mulligan 1988; Miller and Rosman 1989|. The rabbit polyclonal antibody against thymidine kinase of HSV-1 (F) was a gift from W.C. Summers of the Yale University School of Medicine (Liu and Summers 1988), and the mouse monoclonal antibody MCA406 against HSV-1 ICP35 protein (Liu and Roizman 1991) was purchased from Harlan Bioproducts for Sciences, Inc. (Indianapolis, IN). The secondary antibodies used in the Western blots, anti-rabbit or anti-mouse IgGs conjugated with horseradish peroxidase, were purchased from Vector Laboratories, Inc., and Bio-Rad, Inc., respectively.

\section{Construction of plasmids for studies in vivo}

The promoter sequence for U6 small nuclear RNA and a signal for the termination of transcription ( $T$ cluster) by RNA polymerase III (Yuan et al. 1992) were inserted into the EcoRI site of the retroviral vector LXSN (Miller and Rosman 1989) to create pRV0. Retroviral constructs NB2, M1TK, and $\triangle M 1 T K$ were constructed by placing the DNA sequence that coded for the EGS with the ability to target the mRNA for influenza viral protein PB2, M1TK13 RNA, and $\triangle M 1$ (167-377)TK13 RNA under the control of the U6 promoter in plasmid pRV0, respectively. Plasmid pTK129 and pTK141 were constructed, respectively, by placing the BgIII-MluI fragment ( 87 nucleotides) of the HSV-1(F) BamHI Q fragment and BamHI-AccI fragment (181 nucleotides) of the HSV-1 (F) BamHI Z fragment under the control of a phage T3 RNA polymerase promoter. These two fragments correspond to the sequences that encode the 5 ' sequence of TK mRNA and of the overlapping transcripts for the HSV-1 $\alpha 47$, Us 10, and Us 11 genes, respectively (McGeoch et al. 1988). BamHI fragments of HSV-1 (F) were gifts from B. Roizman and M. Liskay (Yale University, New Haven, CT).

\section{Construction of cell lines}

The protocols were modified from Miller and Rosman (1989). In brief, cells were either infected with retroviruses or transfected with retroviral vector DNAs with the aid of a mammalian transfection kit purchased from Strategene, Inc. (La Jolla, CA). After $48 \mathrm{hr}$, neomycin (GIBCO-BRL) was added to the culture medium at a final concentration of $600 \mu \mathrm{g} / \mathrm{ml}$. Cells were subsequently selected in the presence of neomycin for 2 weeks, and neomycin-resistant cells were cloned and allowed to proliferate in neomycin-containing medium (Sambrook et al. 1989). The newly constructed cell lines (NB2, $\triangle$ M1TK, M1TK) and a control cell line in which cells were transfected with $L X S N$ vector DNA, were indistinguishable in terms of cell growth and viability for up to 2 months. Finally, aliquots of these cells were either frozen for long-term storage in liquid nitrogen or used immediately for further studies in vivo.

\section{Viral infection and preparation of RNA and protein extracts}

Approximately $10^{6}$ cells in a T25 flask were either mock-infected or infected with HSV-1 in $1.5 \mathrm{ml}$ of Medium 199 (M199; GIBCO/ supplemented with $1 \%$ fetal calf serum. The moi is specified in the text. After $2 \mathrm{hr}$ of exposure of cells to virus at $37^{\circ} \mathrm{C}$, the medium was replaced with Dulbecco's modified Eagle medium supplemented with $5 \%$ fetal bovine serum. The cells were incubated for $11 \mathrm{hr}$ before harvesting for isolation of viral mRNA and/or protein. RNA and protein extracts were prepared from cells that had either been mock-infected or infected with HSV-1, as described previously (Jenkins and Howett 1984; Liu and Roizman 1991). 


\section{RNase protection assay for viral mRNA expression}

The RNA probes used to detect TK mRNA and the transcripts of the $\alpha 47$, Us10, and Us1 1 genes were synthesized in vitro with T3 RNA polymerase (Promega, Madison, WI) from the DNA templates pTK129 and pTK141, respectively, that had been linearized with Eagl. RNase protection assays were performed as described previously (Yuan et al. 1992). The protected RNA products were separated in $8 \mathrm{M}$ urea $/ 8 \%$ polyacrylamide gels and quantitated with a Phosphorlmager. Quantitation was performed in the linear range of RNA detection.

\section{Electrophoretic separation and staining with antibodies of polypeptides from infected cells}

Denatured, solubilized polypeptides from cell lysates were separated on SDS $-9 \%(\mathrm{vol} / \mathrm{vol})$ polyacrylamide gels. The separated polypeptides were transferred electrically to nitrocellulose membranes and allowed to react in an enzyme-linked immunoassay with antibodies against either mouse or rabbit IgG that had been conjugated with horseradish peroxidase after reaction with antibodies against HSV-1 TK or ICP35. The membranes were subsequently stained with the color development substrate from peroxidase substrate kit purchased from Vector Laboratories, Inc., or reacted with the chemiluminescent substrate in a LumiGLO chemiluminescence kit (Kirkegaard and Perry Laboratories, Inc.) and subsequently subjected to exposure to $\mathrm{X}$-ray film. Finally, the amounts of TK and ICP35 protein on the membrane were quantitated by scanning the films with a densitometer (Bio-Rad, Inc.). Quantitation was performed in the linear range of protein detection.

\section{Acknowledgments}

We are indebted to Drs. Bernard Roizman of the University of Chicago, William Summers, Daniel DiMaio, and Michael Liskay of Yale Medical School for stocks of HSV-1 (F) and cells, retroviral vectors and packaging cell lines, the TK plasmid constructs, and polyclonal antibody against HSV-l|F| TK protein. Thanks also go to Drs. Daniel DiMaio, Bernard Roizman, and William Summers for helpful discussions and for insights into targeting the TK gene in vivo and in vitro. Contributions of materials and help from members of our laboratory (in particular, Y. Yuan and V. Gopalan for helpful discussions and critical reading of the manuscript, and C. Guerrier-Takada and Y. Li for sharing their unpublished results) are greatly appreciated. F.L. is a Parke-Davis postdoctoral fellow of the Life Science Research Foundation. Reports of this work, which was supported by grant GM19422 from the U.S. Public Health Service (to S.A.), were presented at the annual meeting of the Life Sciences Research Foundation (October, 1993) and at the Nineteenth International Herpes Virus Workshop (July 1994).

The publication costs of this article were defrayed in part by payment of page charges. This article must therefore be hereby marked "advertisement" in accordance with 18 USC section 1734 solely to indicate this fact.

\section{References}

Altman, S. 1989. Ribonuclease P: an enzyme with a catalytic RNA subunit. Adv. Enzymol. 62: 1-36.

1993. RNA enzyme-directed gene therapy. Proc. Natl. Acad. Sci. 90: 10898-10900.

Altman, S., L. Kirsebom, and S. Talbot. 1993. Recent studies of ribonuclease P. FASEB I. 7: 7-14.
Ares, M. and A.H. Igel. 1990. Lethal and temperature-sensitive mutations and their suppressors identify an essential structural element in U2 small nuclear RNA. Genes \& Dev. 4: 2132-2145.

Bartkiewicz, M., H. Gold, and S. Altman. 1989. Identification and characterization of an RNA molecule that copurifies with RNase P activity from HeLa cells. Genes \& Dev. 3: 488-499.

Bertrand, E.L. and J.J. Rossi. 1994. Facilitation of hammerhead ribozyme catalysis by the nucleocapsid protein of HIV-l and the heterogeneous nuclear ribonucleoprotien Al. EMBO J. 13: 2904-2912.

Carrara, G., P. Calandra, P. Fruscoloni, G.P. Tocchini-Valentini. 1995. Two helices plus a linker: A reduced substrate for eukaryotic RNase P. Proc. Natl. Acad. Sci. (in press).

Climie, S.C. and J. Friesen. 1988. In vivo and in vitro structural analysis of the rpl/ mRNA leader of Escherichia coli. I. Biol. Chem. 263: 15166-15175.

Coetzee, T., D. Herschlag, and M. Belfort. 1994. Escherichia coli proteins, including ribosomal protein $\mathrm{S} 12$, facilitate in vitro splicing of phage T4 introns by acting as RNA chaperones. Genes \& Dev. 8: 1575-1588.

Danos, O. and R.C. Mulligan. 1988. Safe and efficient generation of recombinant retroviruses with amphotropic and ecotropic host ranges. Proc. Natl. Acad. Sci. 85: 6460-6464.

Darr, S. C., J.W. Brown, and N.R. Pace. 1992. The varieties of ribonuclease P. Trends Biochem. Sci. 17: 178-182.

Das, G., D. Henning, D. Wright, and R. Reddy. 1988. Upstream regulatory elements are necessary and sufficient for transcription of a U6 RNA gene by RNA polymerase III. EMBO I. 7: 503-512.

Ejercito, P.M., E.D. Kieff, and B. Roizman. 1968. Characterization of herpes simplex virus strains differing in their effect on social behavior of infected cells. J. Gen. Virol. 2: 357-364.

Fersht, A. 1985. Enzyme structure and mechanism, 2nd ed. W.H. Freeman and Co., New York.

Forster, A.C. and S. Altman. 1990a. External guide sequence for an RNA enzyme. Science 249: 783-786.

1990b. Similar cage-shaped structure for the RNA components of all ribonuclease $\mathrm{P}$ and ribonuclease MRP enzymes. Cell 62: 407-409.

Frank, D., M. Harris, and N.R. Pace. 1994. Rational design of self-cleaving pre-tRNA-ribonuclease P RNA conjugates. Biochemistry 33: 10800-10808.

Gold, H. and S. Altman. 1986. Reconstitution of RNAase P activity using inactive subunits from $E$. coli and HeLa cells. Cell 44: 243-249.

Guerrier-Takada, C. and S. Altman. 1992. Reconstitution of enzymatic activity from fragments of Ml RNA. Proc. Natl. Acad. Sci. 89: 1266-1270.

Guerrier-Takada, C., K. Gardiner, T. Marsh, N.R. Pace, and S. Altman. 1983. The RNA moiety of RNAase $P$ is the catalytic subunit of the enzyme. Cell 35: 849-857.

Guerrier-Takada, C., A. Van Belkum, C.W.A. Pleij, and S. Altman. 1988. Novel reactions of RNAase $P$ with a tRNA-like structure in turnip yellow mosaic virus RNA. Cell 53: 267272.

Guerrier-Takada, C., N. Lumelsky, and S. Altman. 1989. Specific interactions in RNA enzyme-substrate complexes. Science 286: 1578-1584.

Hampel, A. and R. Tritz. 1989. RNA catalytic properties of the minimum (-)sTRSV sequence. Biochemistry 28: 49294933.

Haseloff, J. and W.L. Gerlach. 1988. Simple RNA enzymes with new and highly specific endoribonuclease activities. Nature 334: 585-591. 
Herschlag, D., M. Khosla, Z. Tsuchihashi, and R.L. Karpel. 1994. An RNA chaperone activity of non-specific RNA binding proteins in hammerhead ribozyme catalysis. EMBO $J$. 13: 2913-2924.

Hutchins, C. J., P.D. Rathjen, A.C. Forster, and R.H. Symons. 1986. Self-cleavage of plus and minus RNA transcripts of avocado sun blotch viroid. Nucleic Acids Res. 14:36273640 .

Inoue, T and T.R. Cech. 1985. Secondary structure of the circular form of the Tetrahymena rRNA intervening sequence: a technique for RNA structure analysis using chemical probes and reverse transcriptase. Proc. Natl. Acad. Sci. 82: 648-652.

Jenkins, F.J. and M.K. Howett. 1984. Characterization of the mRNAs mapping in the BglII $\mathrm{N}$ fragment of the herpes simplex virus type 2 genome. I. Virol. 52: 99-107.

Kahle, D., U. Wehmeyer, and G. Krupp. 1990. Substrate recog nition by RNase P and by the catalytic M1 RNA: identification of possible contact points in pre-tRNAs. EMBO $/ .9$ : 1929-1937.

Kazakov, S. and S. Altman. 1991. Site-specific cleavage by metal ion cofactors and inhibitors of M1 RNA, the catalytic subunit of RNase P from E. coli. Proc. Natl. Acad. Sci. 88: 91939197.

Kikuchi, Y., N. Sasaki-Tozawa, and K. Suzuki. 1993. Artificial self-cleaving molecules consisting of a tRNA precursor and the catalytic RNA of RNase P. Nucleic Acids Res. 21: 46854689.

Li, Y., C. Guerrier-Takada, and S. Altman. 1992. Targeted cleavage of mRNA in vitro by RNase P from Escherichia coli. Proc. Natl. Acad. Sci. 89: 3185-3189.

Liu, F. and S. Altman. 1994. The differential evolution of substrates for an RNA enzyme in the presence and absence of its protein cofactor. Cell 77: 1093-1100.

Liu, F. and B. Roizman. 1991. The promoter, transcriptional unit, and coding sequence of herpes simplex virus 1 family 35 proteins are contained within and in frame with the $U_{L} 26$ open reading frame. I. Virol. 65: 206-212.

Liu, Q-Y. and W.C. Summers. 1988. Site-directed mutagenesis of a nucleotide-binding domain in HSV-1 thymidine kinase: effects on catalytic activity. Virology 163: 638-642.

McClain, W.H., C. Guerrier-Takada, and S. Altman. 1987. Model substrates for an RNA enzyme. Science 238: 527530 .

McGeoch, D.J., M.A. Dalrymple, A.J. Davison, A. Dolan, M.C. Frame, D. McNab, L.J. Perry, J.E. Scott, and P. Taylor. 1988. The complete DNA sequence of the long unique region in the genome of herpes simplex virus type 1. I. Gen. Virol. 69: $1531-1574$

Miller, A.D. and G.J. Rosman. 1989. Improved retroviral vectors for gene transfer and expression. BioTechniques 7: 980-990.

Nolan, J.M., D.H. Burke, and N.R. Pace. 1993. Circularly permuted tRNAs as specific photoaffinity probes of ribonuclease P RNA structure. Science 261: $762-765$.

Peattie, D. and W. Gilbert. 1980. Chemical probes for higherorder structure in RNA. Proc. Natl. Acad. Sci. 77: 46794682.

Reich, C., G.J. Olsen, B. Pace, and N.R. Pace. 1988. Role of the protein moiety of RNase $\mathrm{P}$, a ribonucleoprotein enzyme. Science 239: 178-181.

Roizman, B. and A.E. Sears 1990. Herpes simplex viruses and their replication. In Virology, 2nd ed. (ed. B.N. Fields et al.), pp. 1795-1841. Raven Press, New York.

Rossi, J.J. and N. Sarver. 1990. RNA enzymes (ribozymes) as antiviral therapeutic agents. Trends Biotechnol. 8: 179-183.

Sarver, N., E.M. Cantin, P.S. Chang, J.A. Zaia, P.A. Ladne, D.A
Stephens, and J.J. Rossi. 1990. Ribozymes as potential antiHIV-1 therapeutic agents. Science 247: 1222-1225.

Sambrook, J., E.F. Fritsch, and T. Maniatis. 1989. Molecular cloning: A laboratory manual. 2nd ed. Cold Spring Harbor Laboratory Press, Cold Spring Harbor, New York.

Smith, D. and N.R. Pace. 1993. Multiple magnesium ions in the ribonuclease $\mathrm{P}$ reaction mechanism. Biochemistry 32: 52735281 .

Stein, C.A. and Y.-C. Cheng. 1993. Antisense oligonucleotides as therapeutic agents-Is the bullet really magical? Science 261: 1004-1012.

Tsuchihashi, Z., M. Khosla, and D. Herschlag. 1993. Protein enhancement of hammerhead ribozyme catalysis. Science 262: 99-102.

Uhlenbeck, O.C. 1987. A small catalytic oligoribonucleotide. Nature 328: 596-600.

Vioque, A., J. Amez, and S. Altman. 1988. Protein-RNA interactions in the RNase $\mathrm{P}$ holoenzyme from Escherichia coli. $J$. Mol. Biol. 202: 835-848.

Yu, M., J. Ojwang, O. Yamada, A. Hampel, J. Rapapport, D. Looney, and F. Wong-Staal. 1993. A hairpin ribozyme inhibits expression of diverse strains of human immunodeficiency virus type 1. Proc. Natl. Acad. Sci. 90: 6340-6344.

Yuan, Y. and S. Altman. 1994. Selection in vitro of an extemal guide sequence that direct specific cleavage of mRNA by human RNase P. Science 263: 1269-1273.

- 1995. Substrate recognition by human RNase P: Identification of small, model substrates for the enzyme. $E M B O J$. 14: 159-168.

Yuan, Y., E. Hwang, and S. Altman. 1992. Targeted cleavage of mRNA by human RNase P. Proc. Natl. Acad. Sci. 89: 80068010.

Zaug, A.J., M.D. Been, and T.R. Cech. 1986. The Tetrahymena ribozyme acts like an RNA restriction endonuclease. Nature 324: 429-433. 


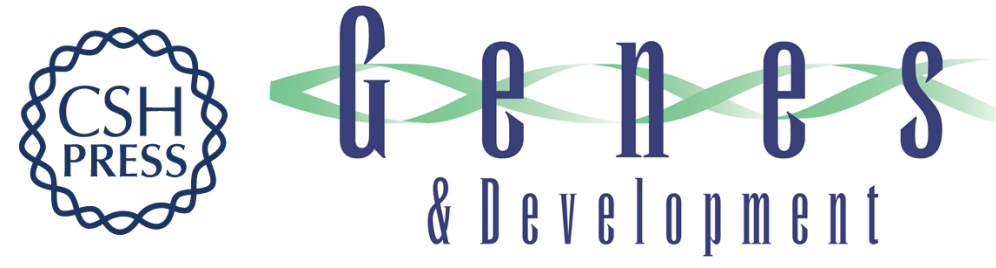

\section{Inhibition of viral gene expression by the catalytic RNA subunit of RNase P from Escherichia coli.}

F Liu and S Altman

Genes Dev. 1995, 9:

Access the most recent version at doi:10.1101/gad.9.4.471

References This article cites 51 articles, 23 of which can be accessed free at: http://genesdev.cshlp.org/content/9/4/471.full.html\#ref-list-1

License

Email Alerting

Service

Receive free email alerts when new articles cite this article - sign up in the box at the top right corner of the article or click here.

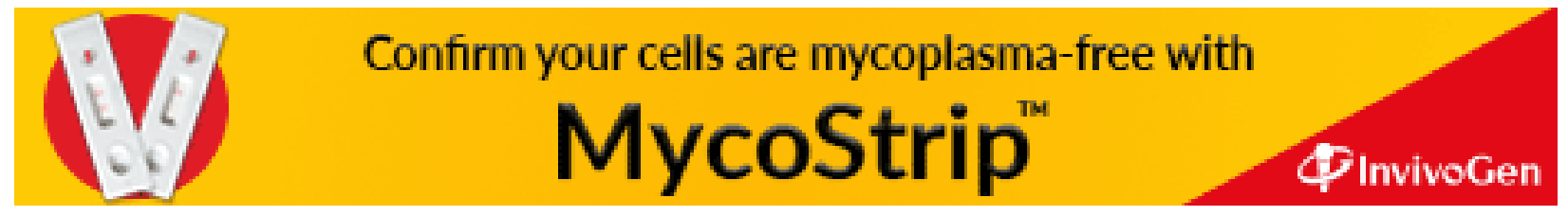

